\title{
Stress response and its relationship to cystic (pseudofollicular) change in the definitive cortex of the adrenal gland in stillborn infants
}

\author{
D. J. DE SA \\ Department of Pathology, McMaster University, Hamilton, Canada
}

SUMMARY The adrenal glands of 41 fresh stillbirths were studied and a 'stress response' pattern could be seen in 28 . In these glands the stress response was characterised by compact cell change, lipid depletion, excess pyroninophilia, and dilatation of the very prominent granular endoplasmic reticulum. Scattered areas of cytolysis of cells, especially of the definitive cortex, gave rise to the commonly seen cystic (pseudofollicular) change and it was obvious that cells undergoing lysis were severely 'stressed'. In 2 infants there was a 'clear cell reversal' pattern. Histological and ultrastructural changes of the stress response were not identified in 11. Infants of low birthweight score were somewhat more commonly represented in the group that did not show a stress response. Cytolytic changes accompanying a stress response were commoner in immature infants. It is argued that cystic (pseudofollicular) change in the adrenal cortex of the newborn signifies a previous stress reaction.

Numerous observers have noted the presence of cystic (pseudofollicular) lesions in the definitive cortex of the adrenal gland in immature infants (Elliot and Armour, 1911; Hett, 1925; Keene and Hewer, 1927; Da Costa, 1928). These workers believed that the cystic lesions represented the remodelling of the definitive cortex to produce the normal zona glomerulosa of the adult gland. This view was questioned by Gruenwald (1946) and Stowens (1966) who regarded the presence of cystic lesions as an abnormal feature of the adrenal cortex. Oppenheimer (1969), and subsequently others (de Sa, 1974; Potter and Craig, 1975), stated that the presence of cystic lesions in the outer, definitive, adult cortex of the adrenal gland represented a manifestation of stress in utero. Becker and Becker (1976) studied the distribution of fat in the adrenal cortex of stillborn infants and described 3 distinct patterns. They did not however attempt to correlate the alterations in lipid with pseudofollicular changes.

The present study reports the findings in 41 fresh stillborn infants. It describes the pattern of a 'stress response' (Symington, 1970) in the adrenal cortex of stillborn infants and the relationship of such a response to the development of cysts.

Received 11 November 1977

\section{Materials and methods}

Forty-one fresh stillbirths were studied. Adrenal tissue was processed for routine histological sectioning, and staining with the methyl green/pyronin reaction (Pappenheim's stain). Frozen sections of fixed adrenal tissue were stained with Oil Red Ot o show neutral lipid. Unstained, frozen sections were examined with polarised light to detect the presence of refractile lipids. In selected cases tissue was fixed in $2 \%$ buffered glutaraldehyde and $1 \mu \mathrm{m}$ eponembedded sections were stained with toluidine blue. Later, ultrathin sections stained with uranyl acetate and lead citrate were studied using the Philips $300 \mathrm{~S}$ electron microscope.

The histological features sought have been described by Symington (1970). They are (a) a diffuse compact cell change, characterised by the presence of plump eosinophilic cells in the cortex instead of the usual pale staining cells with somewhat foamy cytoplasm; (b) reduction of stainable and refractile lipid in the cortex; (c) increased pyroninophilia of the adrenal cortical cells; (d) degeneration (with or without cytolysis) of the cortical cells. As the tissue was fixed, enzyme activity could not be studied.

Details of gestation, birthweight, and complications of pregnancy were obtained from clinical 
records, and the 'birthweight score' (Gruenwald, 1969) was calculated, using the parameters of Usher and McLean (1969).

\section{Results}

Compact cell change. After reviewing the initial $H$ \& $E$ stained sections, it was easy to separate those glands which showed compact cell change from those which did not (Fig. 1a, b). Simultaneous staining of sections from different glands showed that the compact cells had greatly increased eosinophilia and density of the cytoplasm compared with clear cells.

Lipid depletion. Examination of frozen sections of fixed adrenal tissue stained with Oil Red $O$ also showed at least 2 distinct major patterns. It was easy to separate those infants with pronounced lipid depletion from those without such depletion (Fig. $2 a, b)$. The innermost layers of the fetal cortex and the definitive cortex retained small amounts of lipid but the intervening areas of cortex were severely

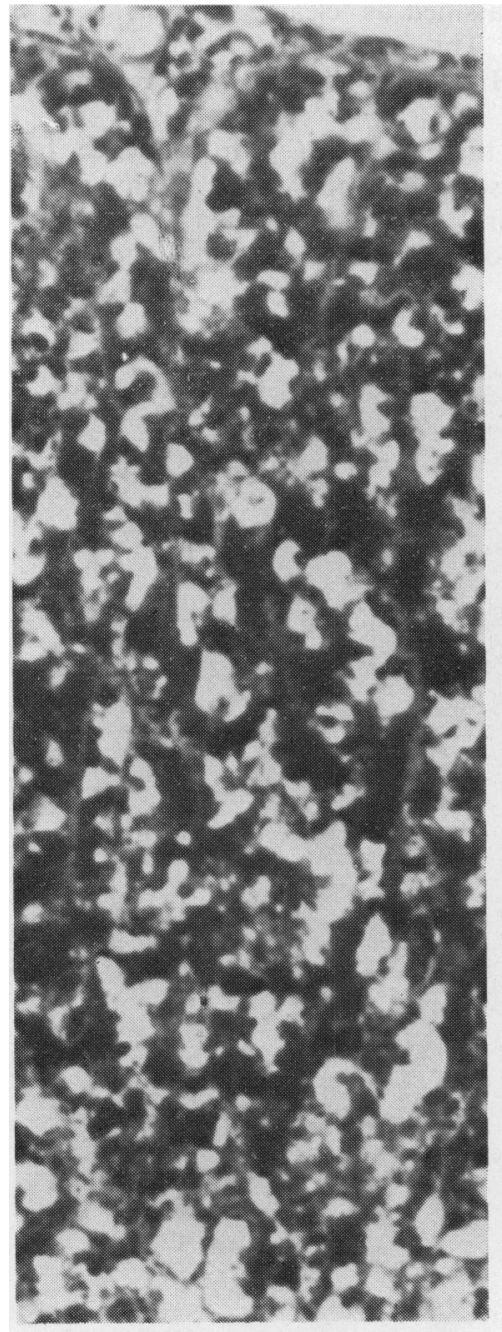

(a)

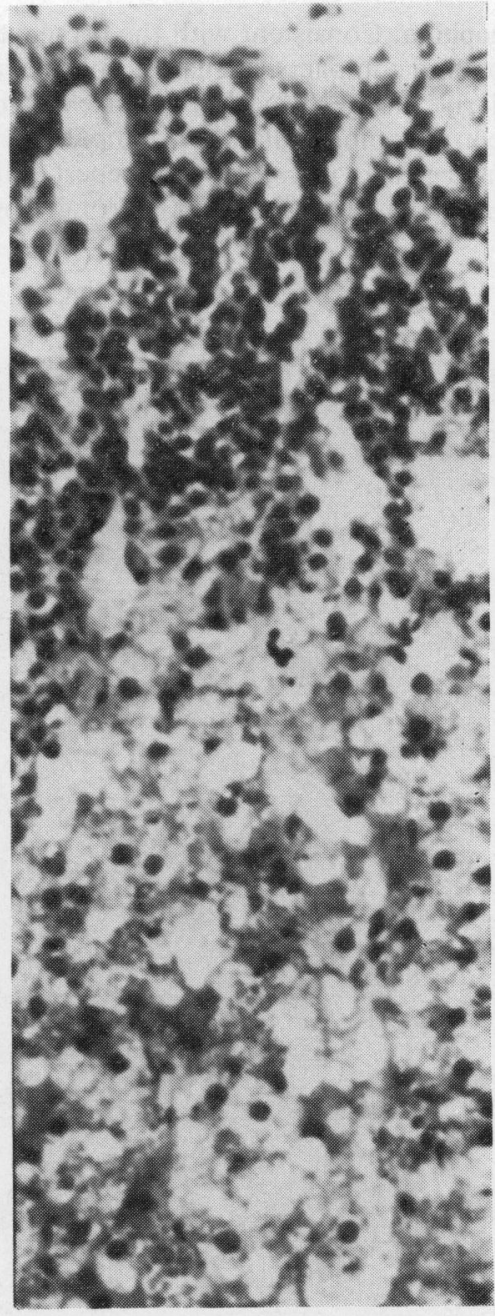

(b)

Fig. 2 Frozen sections of adrenal cortical cells stained with Oil Red $O$ to demonstrate lipid-rich cells in (a) and lipid-depleted cells in (b). In (a) the cytoplasm of the cells is filled with Oil Red $O$ positive lipid which photographs as a diffuse greyish colour. In (b) most Oil Red $O$ stainable material is lost and only scattered minute droplets of fat are present. Frozen section, Oil Red $O(\times 1800)$. 
depleted of lipid. Marked lipid depletion would correspond to the type I change described by Becker and Becker (1976), and the absence of a stress reaction to their type III change.

Patterns of refractile lipid. The distribution of refractile lipids, using unstained frozen sections of the adrenal gland, was identical with that of neutral lipid. Glands depleted of stainable lipid were also depleted of refractile lipid and in all cases the innermost layers of the fetal cortex contained very little refractile lipid in their cytoplasm.

Pyroninophilia. Consistent with the presence of lipid depletion and compact cell change, the relevant cells, particularly those of the adult cortex, showed an increase in pyroninophilia when compared with lipidrich clear cells. It was also the deepest cells of the fetal cortex that were invariably strongly pyroninophilic.
Clear cell reversal. In 2 infants a particularly unusual mottled appearance of the cut surface of the adrenal cortex was noted. This corresponded with an atypical distribution of lipid within the gland when frozen sections stained with Oil Red $O$ were studied. Instead of the usual pattern of distribution of lipid, in these 2 infants, the inner layers of the fetal cortex contained lipid but the outer layers of the cortex were depleted. This corresponded with a pattern of clear cells being present in the inner layers of the fetal cortex but absent in the outer layers. The picture resembled that described by Sarason (1943) and classified as 'clear cell reversal' by Symington (1970). This appearance would correspond to the type II change described by Becker and Becker (1976).

All these features gave evidence for a stress response within the fetal adrenal cortex. Ultrastructural studies confirmed the presence of lipid depletion (Fig. 3a, b), but also showed that in the

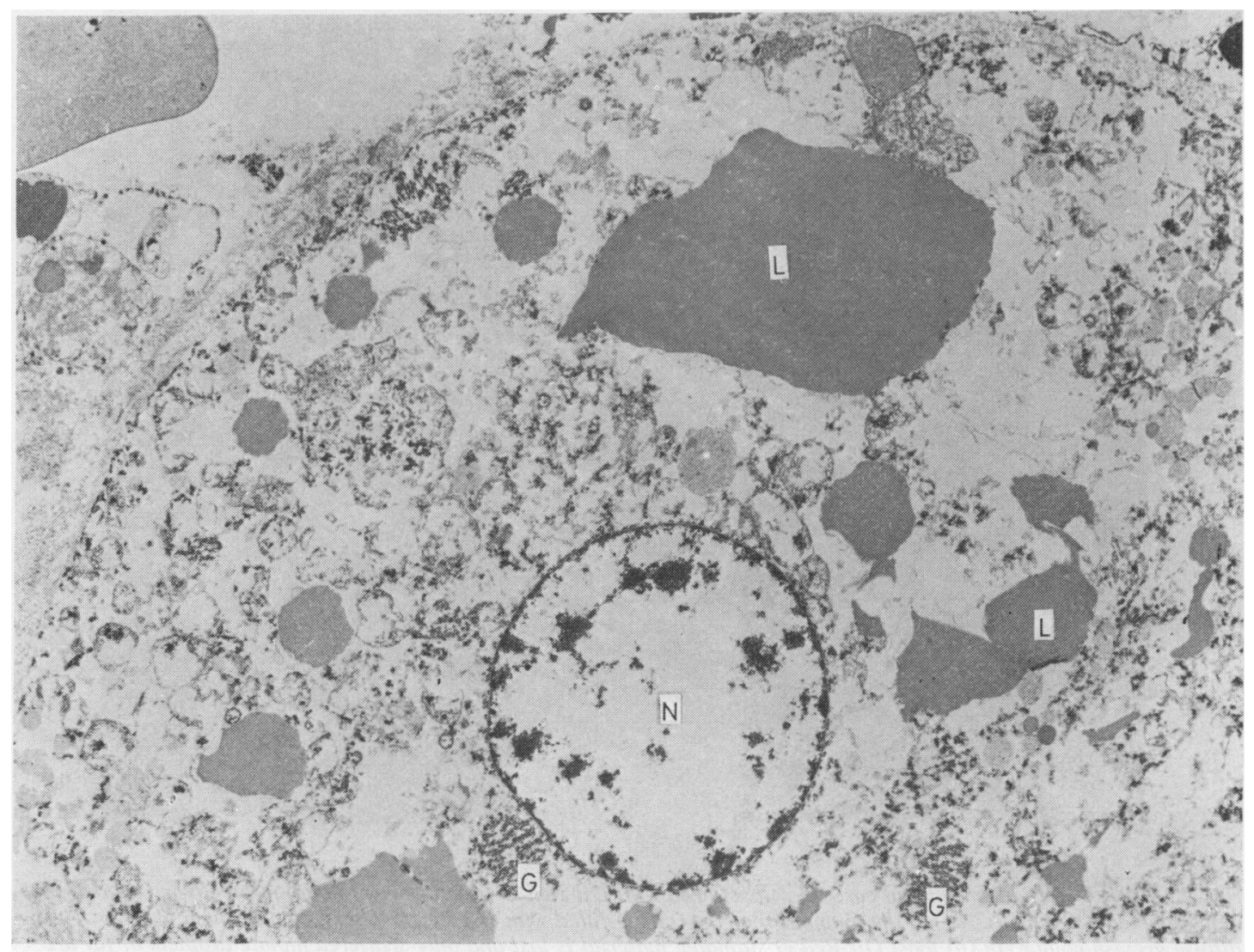

(a) 
lipid-depleted cells the small amounts of lipid that did remain appeared to be predominantly membrane bound. The ultrastructural studies also showed that the lipid-depleted cells had more prominent ribosomes and granular endoplasmic reticulum than their lipid-rich counterparts, particularly in the definitive cortex.

Development of cysts. As noted by many authors, especially by Oppenheimer (1969), the cysts appear to be associated with the cytolysis of small aggregates of cells with pyknotic nuclei and may be associated with the deposition of a proteinaceous coagulum. In some instances haemorrhage into the cyst, which can extend outside the capsule, may be observed. These observations were confirmed in this study. Ultrastructurally the cluster of degenerate cells, whose breakdown leads to the development of the cyst, shows varying degrees of disruption of the cells. In all cases, however, it is clear that the degenerate changes occur in cells showing the features of a marked response to stress (Fig. 4).

Analysis of results in stillbirths. The results have been subdivided into only 3 categories showing normal histology, stress reaction, and clear cell reversal, since it was obvious that those infants with cysts in the outer cortex showed typical features of the stress reaction in each case (Table 1).

A further evaluation of the stress response was undertaken making note of the complications of pregnancy (Table 2) and gestation (Table 3 ). It is obvious that even extremely immature infants can show histological evidence of a well-developed stress

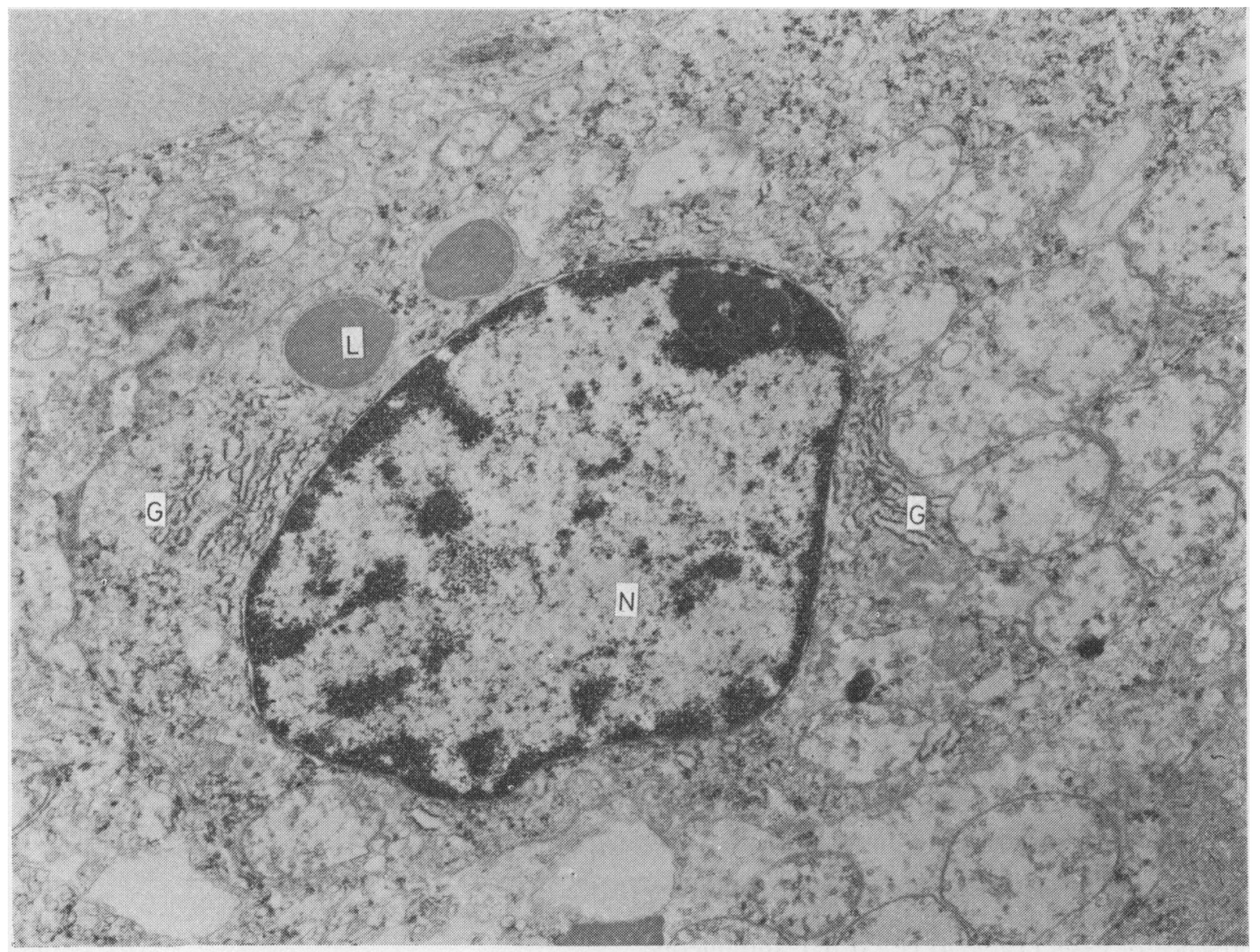

(b)

$\mathbf{N}=$ nucleus, $\mathbf{L}=$ lipid, $\mathbf{G}=$ granular endoplasmic reticulum

Fig. 3 Ultrastructural appearances of a lipid-rich cell $(a)$, and lipid-depleted cell (b), are contrasted. Note large globules of lipid in the lipid-rich cell, in contrast to the small membrane-bound vacuoles of lipid in the depleted cell. Lead citrate, uranyl acetate $(\times 18500)$. 


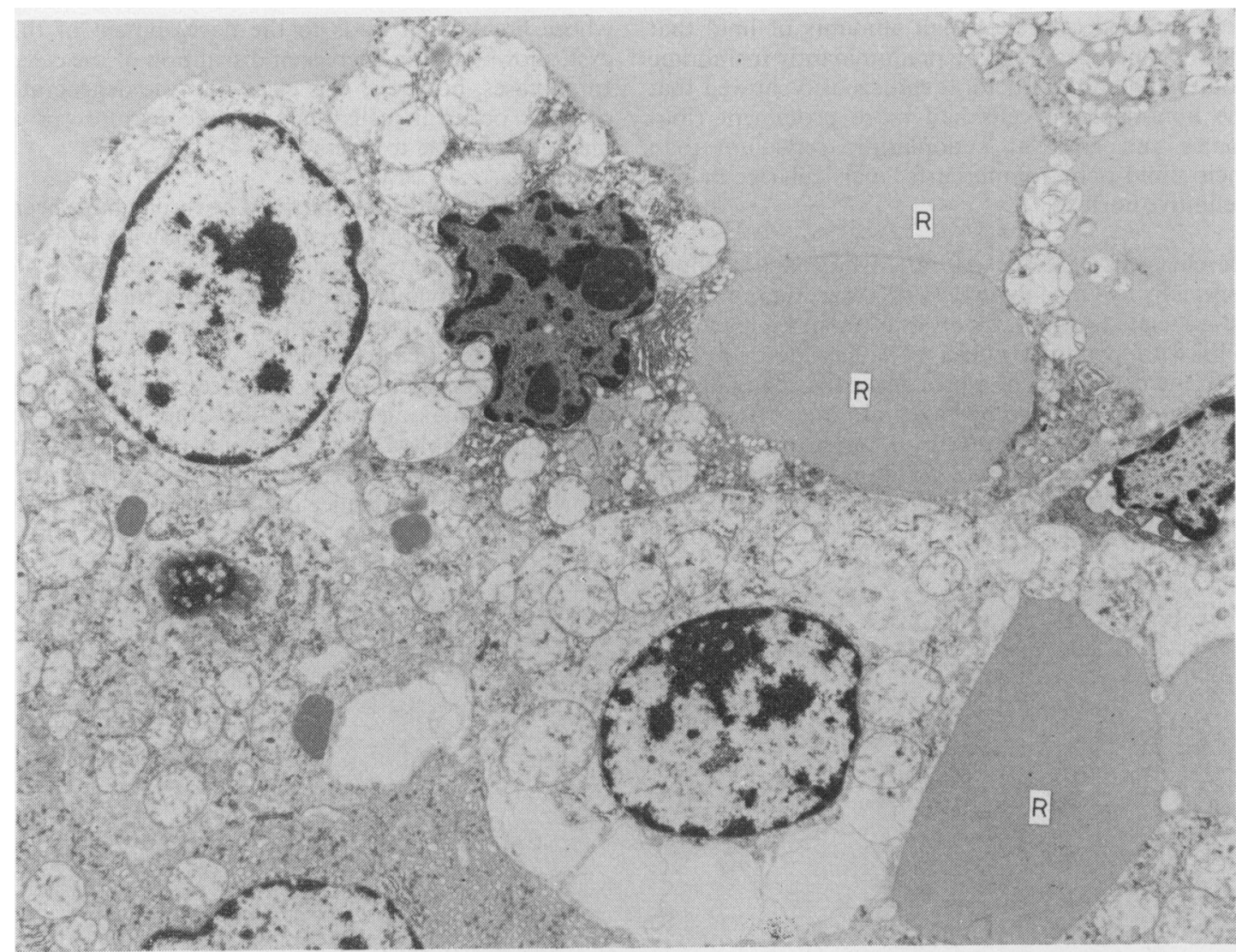

Fig. 4 Parts of at least 7 cells are seen in this zone of cytolysis in the definitive cortex. Note that the cells undergoing lysis have the characteristics of stressed cells and note the abundant red cells present $(R)$. Lead citrate, uranyl acetate $(\times 5750)$.

Table 1 Results in 41 stillbirths

\begin{tabular}{lrrr}
\hline & \multicolumn{2}{c}{ Total } & Presence of cysts \\
\cline { 2 - 3 } & No. & $\%$ & \\
\hline Normal histology & 11 & 27 & 0 \\
Stress reaction & 28 & 68 & 13 \\
Clear cell reversal & 2 & 5 & 1 \\
& 41 & & $14(34 \%)$ \\
\hline
\end{tabular}

reaction and in fact the stress reaction in the very immature infant is usually characterised by the presence of cysts (Table 4$)(P<0 \cdot 05)$. Intrauterine infections and antepartum haemorrhage seem to be most commonly associated with the development of cysts (Table 2). Whether this is due solely to the immature gestation of the affected infants is uncertain (Table 3).
Table 2 Complications of pregnancy and adrenal histology

\begin{tabular}{lllll}
\hline & Normal & Stress & $\begin{array}{l}\text { Stress } \\
\text { and cysts }\end{array}$ & $\begin{array}{l}\text { Clear cell } \\
\text { reversal }\end{array}$ \\
\hline $\begin{array}{l}\text { Antepartum } \\
\text { haemorrhage }\end{array}$ & 2 & 4 & 3 & 1 \\
$\begin{array}{l}\text { Chorioamnionitis } \\
\text { Rhesus }\end{array}$ & 2 & 1 & 7 & - \\
$\quad$ isoimmunisation & 1 & 2 & 1 & 1 \\
$\begin{array}{l}\text { Maternal diabetes } \\
\text { mellitus }\end{array}$ & 1 & 2 & - & - \\
$\begin{array}{l}\text { Viral placentitis } \\
\text { Maternal hypertension } \\
\quad \text { toxaemia }\end{array}$ & 1 & 2 & 2 & - \\
$\begin{array}{l}\text { Congenital } \\
\text { malformation }\end{array}$ & 2 & 2 & - & - \\
\begin{tabular}{l} 
Other causes \\
\hline
\end{tabular} & 2 & 2 & - & - \\
\hline
\end{tabular}

When the birthweight score of the infants is considered (Table 5) it is apparent that infants of low birthweight score are less likely to show evidence of a stress reaction. 
Table 3 Gestation and adrenal histology

\begin{tabular}{lllll}
\hline Fetal age (weeks) & Normal & Stress & $\begin{array}{l}\text { Stress } \\
\text { and cysts }\end{array}$ & $\begin{array}{l}\text { Clear cell } \\
\text { reversal }\end{array}$ \\
\hline$<25$ & 4 & 5 & 5 & $2^{*}$ \\
$25-28$ & 3 & - & 5 & - \\
$29-32$ & - & 3 & 1 & - \\
$33-36$ & 2 & 1 & 1 & - \\
$37-40$ & 2 & 3 & 1 & - \\
$>40$ & - & 3 & - & - \\
\hline
\end{tabular}

*One infant with cysts.

Table 4 Stress patterns, cysts, and gestation

\begin{tabular}{lcccc}
\hline Infants & $\begin{array}{l}\text { Normal } \\
\text { pattern }\end{array}$ & \multicolumn{2}{c}{ Stress patterns } & Total \\
\cline { 3 - 5 } & & \multicolumn{2}{c}{ With cysts } & Without cysts \\
\hline 28 weeks or less & 7 & $11^{*}$ & 6 & 17 \\
28 weeks & 4 & $3^{*}$ & 10 & 13 \\
Total & 11 & 14 & 16 & 30 \\
\hline
\end{tabular}

*The difference in the incidence of cystic change in these 2 groups is significant $\left(\chi^{2}=5 \cdot 237, P<0 \cdot 05\right)$.

Table 5 Birthweight score and stress reaction in infants $>25$ weeks

\begin{tabular}{lll}
\hline Birthweight score & \multicolumn{2}{l}{ No. of cases } \\
\cline { 2 - 3 } & $\begin{array}{l}\text { With normal } \\
\text { pattern }\end{array}$ & $\begin{array}{l}\text { With stress patterns } \\
\text { (incl. } \text { cysts })\end{array}$ \\
\hline+2 & - & 2 \\
+1 & - & 1 \\
0 & 1 & 8 \\
Infants appropriate for or & & \\
$\quad$ larger than mean for & 1 & $11^{*}$ \\
gestational age & 1 & 2 \\
-1 & 5 & 5 \\
-2 & 6 & $7^{*}$ \\
Infants small for gestational & & \\
$\quad$ age & &
\end{tabular}

*The difference in distribution in these 2 categories is significant $\left(\chi^{2}=4.428, P<0.05\right)$

\section{Discussion}

The results presented in this paper are evidence of fetal reactivity to nonspecific stresses in utero and these findings confirm the great variation in the histological appearances of the adrenal cortex described by Becker and Becker (1976). In particular cystic changes and clear cell reversal represent the most extreme changes that may be expected. It is clear that the development of cysts constitutes a somewhat special fetal reaction to stress and is best seen in the most immature fetus. The cells undergoing cytolysis show the ultrastructural and histochemical features of stressed cells and it is tempting to speculate that this represents a biochemical immaturity in cells of the infants' adrenal cortex. Thus such an immature infant might not be capable of responding in a controlled and sustained fashion to an episode of stress. The relatively low incidence of cysts in more mature infants is in keeping with such an interpretation.

It is likely that the ultrastructural photomicrographs of 'normal' fetal adrenal cortical cells (Symington, 1970) probably depict the changes in stressed glands. In particular the presence of membrane-bound lipid vacuoles in some of the cells of the definitive adult cortex accompanied by prominent granular endoplasmic reticulum and an increase in the numbers of free ribosomes occurring in a 20 -week fetus would be in keeping with such an interpretation (Symington, 1970).

This study admittedly raises more questions than it answers. Evidence suggests there is a relationship between the fetal adrenal cortex, the onset of labour, and the maturation of a surfactant system (Liggins, 1969; Kotas and Avery, 1971) and the subject is reviewed by Chiswick (1976). It is tempting to suggest that in those stillbirths with a pronounced stress reaction in their adrenal cortex, the steroids produced probably contributed to the development of pulmonary maturation and possibly even led to the onset of labour. Unfortunately because of the retrospective nature of this study, urinary samples were not collected for steroid analysis nor were any pulmonary pressure or volume curves studied. Clearly a study of this nature should be undertaken as it is likely to give information about endogenous steroid production in stressed states in pregnancy. A further interesting series of studies could be undertaken in those infants with defective steroid synthesis and congenital adrenal hyperplasia (Visser, 1966). The adrenal glands in these infants are known to have an abnormal structure, but they do not appear to have been assessed regarding the presence or absence of a stress response.

The present study does not begin to attempt to answer the question-What happens in those infants who do not show histological evidence of a stress reaction? Some possible parallels may be drawn between the relative infrequency of histological stress in infants of low birthweight, and a temporary lack of a response to cold stress in infants of low birthweight (Hey and Katz, 1969) and diminished steroid production in infants of low birthweight (Cathro et al., 1969). Clearly a great deal of useful information might be gained by undertaking studies to compare endogenous steroid production in the fetus with pulmonary compliance and, in those infants who do not survive 
to compare adrenal histology at necropsy with pulmonary pressure or volume curves. At present, however, our knowledge of steroid production by the human fetus in response to a variety of stresses is incomplete.

\section{References}

Becker, M. J., and Becker, A. E. (1976). Fat distribution in the adrenal cortex as an indication of the mode of intrauterine death. Human Pathology, 7, 495-504.

Cathro, D. M., Forsyth, C. C., and Cameron, J. (1969). Adrenocortical response to stress in newborn infants. Archives of Disease in Childhood, 44, 88-95.

Chiswick, M. L. (1976). Prolonged rupture of membranes, pre-eclamptic toxaemia, and respiratory distress syndrome. Archives of Disease in Childhood, 51, 674-679.

Da Costa, A. C. (1928). Les formations vesiculeuses dans les glandes endocrines. Comptes rendus de l'Association des anatomistes, 23, 69-75.

de Sa, D. J. (1974). Adrenal changes in chorioamnionitis. Archives of Disease in Childhood, 49, 149-151.

Elliot, T. R., and Armour, R. C. (1911). The development of the cortex in the human suprarenal glands and its condition in hemicephaly. Journal of Pathology and Bacteriology, 15, 481-488.

Gruenwald, P. (1946). Embryonic and postnatal development of the adrenal cortex, particularly the zona glomerulosa and accessory nodules. Anatomical Records, 95, 391-421.

Gruenwald, P. (1969). Growth and maturation of the foetus and its relationship to perinatal mortality. In Perinatal Problems, p. 141. Edited by N. R. Butler and E. D. Alberman. Livingstone: Edinburgh.

Hett, J. (1925). Ein Beitrag zu Histogenese der menschlichen Nebenniere. Zeitschrift für mikroskopisch-anatomische Forschung, 3, 179.

\section{Nathalie Masse}

Dr Nathalie Masse, who died in 1975, had been director of teaching at the International Children's Centre for 18 years. She made major contributions to the improvement of child health internationally. In 1976 her friends established a memorial to her, and a fellowship and an international prize were created.

Nathalie Masse Research Fellowship. This fellowship (granted in even-numbered years) has been awarded for the first time for research on nutrition education in a socially deprived region of South America. The next fellowship, to be awarded in 1980, is likewise intended for young research workers. It is intended to help them in their projects directed to problems in social and preventive paediatrics.
Hey, E. N., and Katz, G. (1969). Temporary loss of a metabolic response to cold stress in infants of low birthweight. Archives of Disease in Childhood, 44, 323-330.

Keene, M. F. L., and Hewer, E. E. (1927). Observations on the development of the human suprarenal gland. Journal of Anatomy, 61, 302-324.

Kotas, R. V., and Avery, M. E. (1971). Accelerated appearance of pulmonary surfactant in the fetal rabbit. Journal of Applied Physiology, 30, 358-361.

Liggins, G. C. (1969). Premature delivery of foetal lambs infused with glucocorticoids. Journal of Endocrinology, 45, 515-523.

Oppenheimer, E. H. (1969). Cyst formation in the outer adrenal cortex; studies in the human fetus and newborn. Archives of Pathology, 87, 653-659.

Potter, E. L., and Craig, J. M. (1975). Pathology of the Fetus and Infant, third edition, p. 33. Year Book Medical Publishers: Chicago.

Sarason, E. L. (1943). Adrenal cortex in systemic disease. Archives of Internal Medicine, 71, 702-712.

Stowens, D. (1966). Pediatric Pathology, second edition, pp. 43,711 . Williams and Wilkins: Baltimore.

Symington, T. (1970). Functional Pathology of the Human Adrenal Gland, p. 70. Livingstone: Edinburgh.

Usher, R., and McLean, F. (1969). Intrauterine growth of liveborn Caucasian infants at sea level: standards obtained from measurements in 7 dimensions of infants born between 25 and 44 weeks of gestation. Journal of Pediatrics, 74, 901-910.

Visser, H. K. (1966). The adrenal cortex in childhood. II. Pathological aspects. Archives of Disease in Childhood, 41, 113-136.

Correspondence to Dr J. de Sa, Department of Pathology, McMaster University, 1200 Main Street West, Hamilton, Ontario, Canada L8S 4J9.

International Nathalie Masse Prize. This prize, of 10000 French francs, will be awarded for the first time in 1979, and every 2 years thereafter. It is intended to reward original work concerning childhood, prepared by an institution or by an individual of under 40 years, with a view to encouraging studies by young professionals or research workers.

In both cases, the winners will be chosen without regard to nationality by an international jury.

Details and application forms for the fellowship and the prize from Memorial Committee, International Children's Centre, Château de Longchamp, Bois de Boulogne, 75016 Paris. 